\title{
Longitudinal Ultrasound Velocity and Attenuation in Isotopically Enriched Cadmium
}

\author{
A. S. Bulatov, G. P. Kovtun, V. S. Klochko, A. V. Korniets, \\ D. A. Solopikhin, and A. P. Shcherban'
}

\author{
National Science Center 'Kharkiv Institute of Physics and Technology', \\ 1 Akademichna Str. \\ 61108 Kharkiv, Ukraine
}

The results of the acoustic-properties' study of high-purity $(>99.999 \%)$ cadmium enriched to $66.4 \%$ with the isotope ${ }^{106} \mathrm{Cd}$ and to $82.2 \%$ with the isotope ${ }^{116} \mathrm{Cd}$ are presented for the temperature range of 77-300 K. Isotopic effects are observed in the temperature dependence of the $50 \mathrm{MHz}$ ultrasound propagation velocity and attenuation. A comparison of the sound velocity data for the ${ }^{106} \mathrm{Cd}$ and ${ }^{116} \mathrm{Cd}$ samples has revealed a first-order isotopic effect with a characteristic linear dependence on the isotopes' masses difference, and it determines the phonon-spectrum change caused by the isotope composition. Measuring the attenuation of the longitudinal ultrasound made it possible to detect a second-order isotopic effect with a quadratic dependence on the isotopes' masses difference. The quadratic effect is due to a disordered isotope distribution, and it causes an additional relaxation mechanism for phonon scattering.

Key words: natural cadmium, ${ }^{106} \mathrm{Cd}$ and ${ }^{116} \mathrm{Cd}$ isotopes, isotopic disorder, velocity and attenuation of longitudinal ultrasound.

Представлено результати дослідження акустичних властивостей високочистого (>99,999\%) кадмію, збагаченого до $66,4 \%$ ізотопом ${ }^{106} \mathrm{Cd}$ i до $82,2 \%$ ізотопом ${ }^{116} \mathrm{Cd}$, у температурній області 77-300 К. Ізотопічні ефекти спостерігалися на температурній залежності швидкости поширення та згасання ультразвуку частотою у 50 МГц. Порівняння даних для швидкости звуку зразків ${ }^{106} \mathrm{Cd} \mathrm{i}{ }^{116} \mathrm{Cd}$ виявляє ізотопічний ефект першого порядку

Corresponding author: A. S. Bulatov

E-mail: bulatov@kipt.kharkov.ua

Citation: A. S. Bulatov, G. P. Kovtun, V. S. Klochko, A. V. Korniets, D. A. Solopikhin, and A. P. Shcherban', Longitudinal Ultrasound Velocity and Attenuation in Isotopeally Enriched Cadmium, Metallofiz. Noveishie Tekhnol., 40, No. 11: 14651473 (2018), DOI: $10.15407 /$ mfint.40.11.1465. 
з характерною лінійною залежністю від ріжниці мас ізотопів і визначає зміну фононного спектру з ізотопним складом. Міряння згасання поздовжнього ультразвуку уможливило виявити ізотопічний ефект другого порядку з квадратичною залежністю від ріжниці мас ізотопів. Квадратичний ефект пов'язаний з неупорядкованим розподілом ізотопів і зумовлює додатковий релаксаційний механізм розсіяння фононів.

Ключові слова: природній кадмій, ізотопи ${ }^{106} \mathrm{Cd} \mathrm{i}{ }^{116} \mathrm{Cd}$, ізотопічний безлад, швидкість і згасання поздовжнього ультразвуку.

Представлены результаты исследования акустических свойств высокочистого (>99,999\% ) кадмия, обогащённого до $66,4 \%$ по изотопу ${ }^{106} \mathrm{Cd}$ и до $82,2 \%$ по изотопу ${ }^{116} \mathrm{Cd}$, в температурной области 77-300 К. Изотопические эффекты наблюдались на температурной зависимости скорости распространения и затухания ультразвука частотой 50 МГц. Сравнение данных для скорости звука образцов ${ }^{106} \mathrm{Cd}$ и ${ }^{116} \mathrm{Cd}$ выявляет изотопический эффект первого порядка с характерной линейной зависимостью от разности масс изотопов и определяет изменение фононного спектра с изотопным составом. Измерение затухания продольного ультразвука позволило обнаружить изотопический эффект второго порядка с квадратичной зависимостью от разности масс изотопов. Квадратичный әффект связан с неупорядоченным распределением изотопов и обусловливает дополнительный релаксационный механизм рассеяния фононов.

Ключевые слова: природный кадмий, изотопы ${ }^{106} \mathrm{Cd}$ и ${ }^{116} \mathrm{Cd}$, изотопический беспорядок, скорость и затухание продольного ультразвука.

(Received May 4, 2018)

\section{INTRODUCTION}

A successful development of a new line in applied physics, viz., isotope engineering of materials, has made possible the production of isotopically enriched chemical elements in reasonable amounts [1]. This has caused particular attention to investigating their physical properties [2-5]. Generally, the isotope (mass) effects in crystals are divided into two types of manifestation. The first one represents the dependence of the properties on the average atomic mass $M_{c}$ of each chemical element constituting the atom $\left(M_{c}=\sum_{i} c_{i} M_{i}, c_{i}, M_{i}\right.$ are, respectively, the concentration and the mass of the $i$-th isotope). The second type represents the dependence of crystal properties on the isotopic disorder factor $q$, which is proportional to the $\left(\frac{\Delta M_{i}}{M_{c}}\right)^{2}$ ratio, where $\Delta M_{i}=M_{i}-M_{c}$. This type of the effect is not too large owing to the smallness of $\Delta M_{i}$, and it is absent in monoisotope and isotopically ordered crystals. As things 
now stand, the most extensive studies of isotopic effects have been performed on semiconductor single crystals such as carbon (diamond), silicon and germanium, whereas the information on pure metals is limited to the electric resistance measurements in a polycrystalline state of lithium [6] and cadmium [7] isotopes. It should be noted that the investigation of isotopic effects in cadmium metal is of interest, because its natural composition includes eight stable isotopes: ${ }^{106} \mathrm{Cd},{ }^{108} \mathrm{Cd}$, ${ }^{110} \mathrm{Cd},{ }^{111} \mathrm{Cd},{ }^{112} \mathrm{Cd},{ }^{113} \mathrm{Cd},{ }^{114} \mathrm{Cd},{ }^{116} \mathrm{Cd}$. Cadmium surpasses $\mathrm{C}, \mathrm{Si}, \mathrm{Ge}$ in the number of isotopes without showing predominant content of any of the isotopes. So, the cadmium metal may be expected to change its properties with the enrichment in one of its isotopes. A particular attention should be given to the isotopes ${ }^{106} \mathrm{Cd}$ and ${ }^{116} \mathrm{Cd}$ not only from the scientific point of view, but also from the position of practical applications. For example, using them as the base, unique high-resolution and ultralow-background scintillators are created for investigating the properties of neutrino and weak interactions, for searching the effects beyond the framework of the standard model of elementary particles [8-10].

The present work first deals with the ultrasonic properties of highpurity cadmium enriched in ${ }^{106} \mathrm{Cd}$ and ${ }^{116} \mathrm{Cd}$ isotopes. The isotopic effects were observed in the temperature dependence $(77-300 \mathrm{~K})$ of the propagation velocity and attenuation of longitudinal ultrasound of 50 $\mathrm{MHz}$ frequency. In the temperature range under study, cadmium undergoes no phase transformations.

\section{EXPERIMENTAL TECHNIQUE AND SAMPLES}

Low-temperature ultrasonic studies were carried out in the pulsed mode by the phase-sensitive bridge method. The longitudinal acoustic waves were generated and detected by lithium niobate piezoelectric transducers. The acoustic sample-transducer contact was provided by silicone lubricant. The measuring equipment has enabled us to determine (at the given temperature and in one experiment) both the longitudinal ultrasound velocity $V_{L}$ and the relative ultrasonic attenuation $\Delta \alpha_{L}$. The error in the measurements was no more than $\pm 0.2 \%$ and $1 \%$, respectively. The studies were performed at temperature scanning $\Delta T=1-2 \mathrm{~K}$ and at a temperature control to an accuracy of $\pm 0.05 \mathrm{~K}$ in a single measurement. Table 1 gives the absolute isotope composition of the ${ }^{106} \mathrm{Cd}$, ${ }^{116} \mathrm{C}$, and ${ }^{\text {nat }} \mathrm{Cd}$ (natural) samples obtained by massspectrometry analysis.

To obtain reliable experimental data, it was necessary to compare the isotope samples identical in the chemical impurity composition and in structural characteristics. In the present experiments, the first requirement was fully fulfilled due to carrying out the procedures of deep refining by filtration with heating and distillation, which provid- 
TABLE 1. Absolute isotope composition of the ${ }^{106} \mathrm{Cd},{ }^{116} \mathrm{Cd}$, and ${ }^{\text {nat }} \mathrm{Cd}$ samples.

\begin{tabular}{c|ccc}
\hline $\begin{array}{c}\text { Cd atomic mass, } \\
\text { a.m.u. }\end{array}$ & Enriched in ${ }^{106} \mathrm{Cd}, \%$ & Enriched in ${ }^{116} \mathrm{Cd}, \%$ & Natural ${ }^{\mathrm{nat}} \mathrm{Cd}, \%$ \\
\hline 106 & $66.4 \pm 0.4$ & $0.11 \pm 0.04$ & $1.25 \pm 0.06$ \\
108 & $6.58 \pm 0.05$ & $0.1 \pm 0.05$ & $0.89 \pm 0.03$ \\
110 & $5.06 \pm 0.05$ & $1.8 \pm 0.03$ & $12.49 \pm 0.18$ \\
111 & $4.83 \pm 0.01$ & $2.01 \pm 0.02$ & $12.80 \pm 0.12$ \\
112 & $8.85 \pm 0.02$ & $4.35 \pm 0.08$ & $24.13 \pm 0.21$ \\
113 & $4.38 \pm 0.05$ & $2.14 \pm 0.03$ & $12.22 \pm 0.05$ \\
114 & $8.77 \pm 0.09$ & $7.30 \pm 0.07$ & $28.73 \pm 0.42$ \\
116 & 1.497 & $82.2 \pm 0.1$ & $7.49 \pm 0.18$ \\
\hline
\end{tabular}

ed the total purity of $\mathrm{Cd}>99.999 \%$ [8]. Since the samples were made as $\varnothing 3.9 \times 5 \mathrm{~mm}$ long cylindrical ingots, to attain the homogeneous structural condition of the samples, all technological stages of their manufacturing were carefully controlled. The polycrystalline ingots had a coarse-grained structure with the crystal size being $\cong 0.2 \mathrm{~mm}$. The density of the samples was determined by the hydrostatic weighing method. The X-ray diffractometry measurements have revealed that the samples show the axial crystallographic texture with growth orientation [001], inclined at an angle of $50^{\circ} \pm 2^{\circ}$ to the cylindrical axis. The creation of isotropic polycrystalline $\mathrm{Cd}$ metal samples with the facecentred close-packed (f.c.c.p.) lattice presents a rather difficult problem because of a high elastic anisotropy and a low recrystallization temperature of cadmium. The only rational method of obtaining reliable data in this situation seemed to fulfil multiple independent measurements. In this connection, eleven series of independent experiments were carried out for each isotope sample taken separately. At the same time, the scatter of the independent measurement results provides the possibility of estimating the degree of their reliability. After an individual series of experiments, the sample was held for 48 hours at room temperature in order to eliminate possible residual stresses experienced during 'cooling-heating' thermal cycle.

\section{RESULTS AND DISCUSSION}

\subsection{Longitudinal Sound Velocity}

Figure 1 illustrates temperature dependences of elastic longitudinal wave propagation velocities $V_{L}(T)$ of $50 \mathrm{MHz}$ frequency in the temperature range from 77 to $300 \mathrm{~K}$ for cadmium samples isotopically enriched 


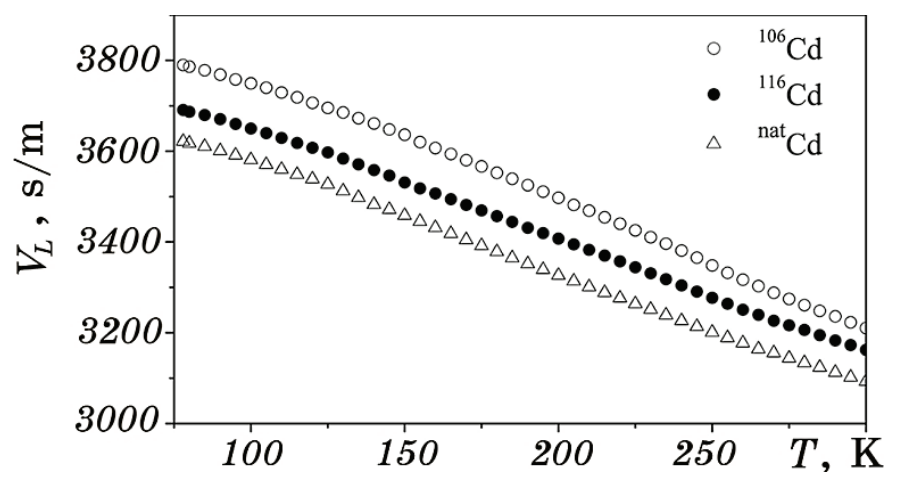

Fig. 1. Temperature dependence of $50 \mathrm{MHz}$ elastic longitudinal wave propagation velocity in cadmium.

in ${ }^{106} \mathrm{Cd},{ }^{116} \mathrm{Cd}$ and natural ${ }^{\text {nat }} \mathrm{Cd}$.

Table 2 lists the values of average atomic masses $M_{c}$ and the density $\rho$ of cadmium samples.

As it follows from Fig. 1, the behaviour of the functions $V_{L}(T)$ remains practically the same for all cadmium samples, the only difference being the linear shift of the temperature dependences with the change in the isotope composition. This manifestation of the linear character of the isotopic effect directly testifies to the influence of the isotope composition on the phonon spectrum deformation. In the quasiharmonic model of the phonon-phonon interaction, without consideration of the isotopic disorder, the linearity of the first-order isotopic effect is due just to the phonon frequency shift $\Delta w_{i}$ of specific phonon modes inversely proportional to $\sqrt{M_{c}}$. In this case, the following condition is fulfilled for the phonon modes of any isotope composition, viz., the magnitude of effective power parameters is independent of the mean mass value $M_{c}$ of the isotope, because the electron shell configuration of atoms is rather weakly dependent on the nuclear size.

In Refs. [6, 7, 11, 12], using lithium, cadmium and germanium isotopes as examples, in the quasi-harmonic approximation, consideration has been given to the influence of the isotope composition on the

TABLE 2. The values of average atomic masses $M_{c}$ and the density $\rho$ of cadmium samples.

\begin{tabular}{cc|c|c}
\hline No. & $\mathrm{Cd}$ & $M_{c}$, a.m.u. & $\rho, \mathrm{g} / \mathrm{cm}^{3}$ \\
\hline 1 & 106 & 108.15 & 8.2921 \\
2 & Nat. & 112.508 & 8.6592 \\
3 & 116 & 115.384 & 8.8602 \\
\hline
\end{tabular}




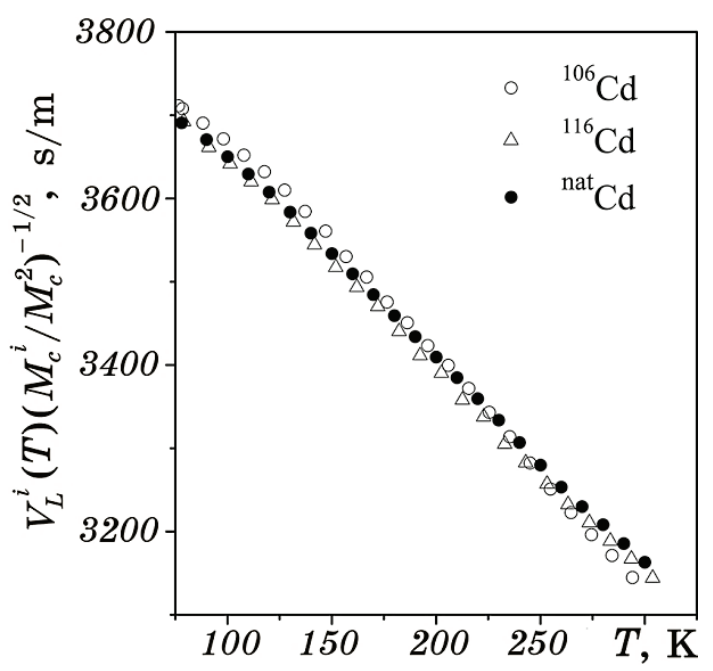

Fig. 2. Universal relation between the reduced longitudinal ultrasound velocity $V_{L}^{(i)}(T)\left(M_{c}^{(i)} / M_{c}^{(2)}\right)^{-1 / 2}$ and the reduced temperature $T^{*}$ for Cd isotopes.

temperature dependence of electrical resistance, thermal expansion, lattice constant and elastic moduli. It has appeared that the parameters of the properties of the samples different in the isotope composition are related to a first approximation by the universal relation, which obviously demonstrates the linearity in the isotopes' masses difference in the effect. Taking into account this consideration of the first-order isotopic effect, our measurements of $V_{L}(T)$ can be similarly represented by the relations $V_{L}^{(i)}(T)=V_{L}^{(2)}\left(T^{*}\right) \sqrt{\frac{M_{c}^{(2)}}{M_{c}^{(i)}}}, \quad T^{*}=T \sqrt{\frac{M_{c}^{(i)}}{M_{c}^{(2)}}}$, which are dependent only on the ratio of masses of the compared samples, where $M_{c}^{(2)}$ is the stated isotope composition of mass 2 (Table 2); $M_{c}^{(i)}$ is the mass of the arbitrary isotope composition $i$. This result is depicted in Fig. 2, where the reduced velocity $V_{L}^{(i)} \sqrt{\frac{M_{c}^{(i)}}{M_{c}^{(2)}}}$ is plotted along the axis of ordinates, and the reduced temperature $T^{*}$ is laid off on the abscissa axis.

\subsection{Attenuation of Longitudinal Sound}

Figure 3 illustrates the temperature dependence of sound attenuation $\Delta \alpha_{L}^{i}(T)$ in the ${ }^{\text {nat }} \mathrm{Cd},{ }^{106} \mathrm{Cd}$, and ${ }^{116} \mathrm{Cd}$ samples. For visual demonstration of the effect of isotope composition on the sound attenuation, the set of 


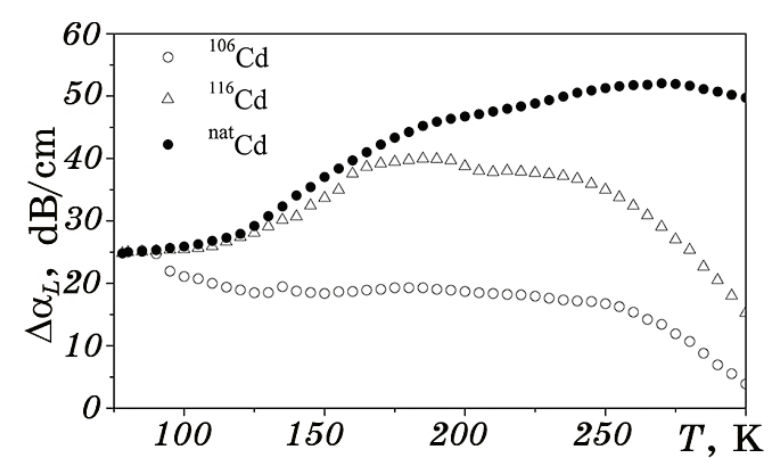

Fig. 3. Temperature dependence of normalized attenuation of longitudinal ultrasonic waves of $50 \mathrm{MHz}$ frequency in natural and isotope composition cadmium.

relative measurement data on $\Delta \alpha_{L}^{i}(T)$ has been normalized to a common value of attenuation at a temperature of $77 \mathrm{~K}$, which is the starting value in all the measurements.

The measurements were realized at the conditions corresponding to the phonon-phonon mechanism of Akhiezer's absorption, this being testified by the characteristic $S$-shaped function $\Delta \alpha_{L}^{\text {nat }}(T)$ for the natural isotope composition.

The isotope enrichment substantially changes the shape of $\Delta \alpha_{L}^{i}(T)$ curves, and this is indicative of the contribution of isotopic scattering to the sound attenuation. In the isotope-enriched crystals representing isotope mixtures, owing to their mass difference at the lattice sites, and because of the presence of static disorder, the dynamic disordering arises, i.e., the amplitude and phase of vibrations of a separate impurity isotope differ from those of the isotopes forming the matrix. The dynamic disordering violates the translational invariance of the metal lattice, and the phonons of the impurity isotope are not pure intrinsic states of the harmonic Hamiltonian of the crystal (matrix) [3]. Note that the isotopic phonon-phonon scattering is independent of the temperature, and continuously contributes to the volumetric attenuation of the longitudinal sound. The relaxation rate of the temperatureindependent isotopic scattering is proportional to the biquadrate of the phonon wave vector and to the isotopic disorder factor $q=\sum_{i} C_{i}\left(\frac{\Delta M_{i}}{M_{c}}\right)^{2}$ [13]. The $q$ values for cadmium samples are indicated in Table 3.

In going from ${ }^{\text {nat }} \mathrm{Cd}$ to the sample enriched in ${ }^{106} \mathrm{Cd}$ to $66.4 \%$, the $q$ factor shows nearly a three-fold increase, and this is reflected in the radical difference between the temperature dependences of the sound. 
TABLE 3. The values of the isotopic disorder factor for cadmium samples.

\begin{tabular}{c|c|c|c}
\hline $\mathrm{Cd}$ & Nat. & 106 & 116 \\
\hline$q$ & $2.7 \cdot 10^{-4}$ & $8.8 \cdot 10^{-4}$ & $1.6 \cdot 10^{-4}$ \\
\hline
\end{tabular}

The unusual shape of the function $\Delta \alpha_{L}^{106}(T)$ directly points to the dominant role of isotopic scattering in the longitudinal sound attenuation in cadmium. When passing to the sample enriched in ${ }^{116} \mathrm{Cd}$ to $82.2 \%$, the $q$ factor value decreases by a factor of 1.7 , but the general behaviour of the function $\Delta \alpha_{L}^{116}(T)$ remains similar to that of $\Delta \alpha_{L}^{\text {nat }}(T)$. High enrichment provides the condition close to the monoisotope state, and that appreciably reduces the level of the isotopic scattering effect on the longitudinal sound attenuation. Finally, it may be said that, according to preliminary data of the present work, the transverse sound in cadmium is in many respects sensitive to the isotopic disorder, and exhibits more clearly the isotopic scattering effect in the sound attenuation.

\section{CONCLUSIONS}

Thus, low-temperature $(77$ to $300 \mathrm{~K})$ ultrasonic properties of highpurity cadmium (>99.999\%) enriched up to $66.4 \%$ and $82.2 \%$ in the ${ }^{106} \mathrm{Cd}$ and ${ }^{116} \mathrm{Cd}$ isotopes, respectively, have been investigated for the first time. The obtained results can be summarized as follow.

1. The precision measurements of the temperature dependence of the longitudinal elastic sound wave $(50 \mathrm{MHz})$ velocity have revealed the first-order isotopic effect caused by the influence of isotope masses on the phonon spectrum. The linear isotopic effect has been described in terms of the universal relation dependent only on average isotope masses in crystals.

2 . The investigations on the temperature dependences of longitudinal elastic ultrasound attenuation have allowed us to observe, for the first time, the second-order isotopic effect, viz., isotopic phonon-phonon scattering, and also, to estimate its direct contribution to sound attenuation by the isotopic disorder factor.

\section{REFERENCES}

1. V. G. Plekhanov, Uspekhi Fizicheskikh Nauk, 170, No. 11: 1245 (2000) (in Russian).

2. A. P. Zhernov and A. V. Inyushkin, Uspekhi Fizicheskikh Nauk, 171, No. 8: 827 (2001) (in Russian).

3. A. P. Zhernov and A. V. Inyushkin, Uspekhi Fizicheskikh Nauk, 172, No. 5: 573 (2002) (in Russian).

4. W. Schnelle and E. Gmelin, J. Phys. Cond. Matter, 13, No. 27: 6087 (2001). 
5. A. V. Gusev, A. M. Gibin, I. A. Adryuschenko, V. A. Gavva, and E. A. Kozyrev, Fizika Tverdogo Tela, 57, No. 9: 1868 (2015) (in Russian).

6. N. A. Babushkina, A. P. Zhernov, and A. V. Inyushkin, Zhurnal Ehksperimental'noy i Teoreticheskoy Fiziki, 82, No. 3: 793 (1982) (in Russian).

7. G. Kh. Panova and B. N. Samoylov, Zhurnal Ehksperimental'noy $i$ Teoreticheskoy Fiziki, 53, No. 5: 1539 (1967) (in Russian).

8. G. P. Kovtun, A. P. Shcherban', D. A. Solopikhin, V. D. Virich, V. I. Zelenskaja, R. S. Boiko, F. A. Danevich, V. M. Kudovbenko, and S. S. Nagorny, Functional Materials, 18, No. 1: 121 (2011).

9. P. Belli, R. Bernabei, R. S. Boiko, V. B. Brudanin, N. Bukilic, R. Cerulli, D. M. Chernyak, F. A. Danevich, S. d'Angelo, V. Ya. Degoda, A. E. Dossovitskiy, E. N. Galashov, Yu. A. Hyzhnyi, S. V. Ildyakov, A. Incicchitti, V. V. Kobychev, O. S. Kolesnyk, G. P. Kovtun, V. M. Kudovbenko, J. R. de Laeter, A. L. Mikhlin, S. S. Nagorny, S. G. Nedilko, A. S. Nikolaiko, S. Nisi, D. V. Poda, R. B. Podviyanuk, O. G. Polischuk, D. Prosperi, A. P. Shcherban, V. P. Shcherbatsky, V. N. Shlegel, D. A. Solopikhin, Yu. G. Stenin, V. I. Tretyak, Ya. V. Vasiliev, and V. D. Virich, Nucl. Instr. Meth. Phys Res., 615, Iss. 3: 301 (2010).

10. A. S. Barabash, P. Belli, R. Bernabei, R. S. Boiko, F. Cappella, V. Caracciolo, D. M. Chernyak, R. Cerulli, F. A. Danevich, M. L. Di Vacri, A. E. Dossovitskiy, E. N. Galashov, A. Incicchitti, V. V. Kobychev, S. I. Konovalov, G. P. Kovtun, V. M. Kudovbenko, M. Laubenstein, A. L. Mikhlin, S. Nisi, D. V. Poda, R. B. Podviyanuk, O. G. Polischuk, A. P. Shcherban, V. N. Shlegel, D. A. Solopikhin, Yu. G. Stenin, V. I. Tretyak, V. I. Umatov, Ya. V. Vasiliev, and V. D. Virich, J. Instrumentation, 06: P08011 (2011).

11. V. I. Ozhogin, N. A. Babushkina, L. M. Belova, A. P. Zhernov, Yu. Heller, and K. Itoh, Zhurnal Ehksperimental'noy i Teoreticheskoy Fiziki, 115, No.1: 243 (1999) (in Russian).

12. A. P. Zhernov, Fizika Nizkikh Temperatur, 26, No. 12: 1226 (2000) (in Russian).

13. P. G. Klemens, Proceedings of the Royal Society of London. Ser. A, Math. Phys. Sci., 68: 1113 (1995). 